\title{
Results of Adults Laparoscopic Varicocelectomy in a Limited Setting: A Study in Yaoundé (Cameroon)
}

\author{
Landry Oriole Mbouché1, Guy Aristide Bang1, Axel Stéphane Nwaha Makon', \\ Frantz Guy Epoupa Ngallé1, Eric Patrick Savom1', Roland Metomo', Junior Mekeme Mekeme1, \\ Achille Aurèle Mbassi², Justin Kamga ${ }^{2}$, Blondel Nana Oumarou ${ }^{2}$
}

\begin{abstract}
${ }^{1}$ Department of Surgery and Specialities, Faculty of Medicine and Biomedical Sciences, Yaoundé, Cameroon
${ }^{2}$ The National Insurance Fund Health Center of Essos, Yaoundé, Cameroon

Email: landrymbouche@gmail.com, guyaristidebang@yahoo.fr, nwahamakon@gmail.com, frantzepoupa@gmail.com, esavom@yahoo.fr,metomo.rs@gmail.com,juniormekeme@yahoo.fr,drmbassi@yahoo.com,drkamgajustin@yahoo.fr, nanablondel@yahoo.com
\end{abstract}

How to cite this paper: Mbouché, L.O., Bang, G.A., Makon, A.S.N., Ngallé, F.G.E., Savom, E.P., Metomo, R., Mekeme, J.M., Mbassi, A.A., Kamga, J. and Oumarou, B.N. (2021) Results of Adults Laparoscopic Varicocelectomy in a Limited Setting: A Study in Yaoundé (Cameroon). Open Journal of Urology, 11, 443-451.

https://doi.org/10.4236/oju.2021.1112044

Received: October 10, 2021

Accepted: December 3, 2021

Published: December 6, 2021

Copyright $\odot 2021$ by author(s) and Scientific Research Publishing Inc. This work is licensed under the Creative Commons Attribution International License (CC BY 4.0).

http://creativecommons.org/licenses/by/4.0/

\begin{abstract}
Background: Varicocele is an abnormal dilation and tortuosity of the internal spermatic veins within the pampiniform plexus veins draining the testicle. The principle of varicocele treatment is to block the reflux in the internal spermatic vein while preserving the internal spermatic artery, lymphatics and vas deferens. Treatment can be performed through percutaneous venous embolization or surgical correction, either open or laparoscopic approach. The purpose of the study was to review our experience in the management of laparoscopic varicocele repair and to assess the outcomes after operation. Methods: We retrospectively reviewed files of patients who underwent laparoscopic varicocelectomy from January 2010 to December 2009 in three health center of Yaoundé (Cameroon). Clinical and diagnosis features of varicocele, indication for surgery, operative procedure and outcomes, as well as long-term follow-up of were analyzed. Results: A total of 74 file of patients were collected. The average age of patients was 36.93 years old. Among them, $43(58.11 \%)$ had varicocele grade $1,21(28.38 \%)$ grade 2 , and $2(2.70 \%)$ grade 3. Fifty-four (72.97\%) cases had bilateral varicocele, $17(22.97 \%)$ and 3 (4.05\%) patients had left and right varicocele respectively. 42(56.7\%) patients complained for fertility problem. Scrotal pain was found in $26(35.13 \%)$ cases. The pneumoperitoneum was achieved in all cases through a supra-umbilical open coelioscopy with the insertion of a $10 \mathrm{~mm}$-optic port. Two $5 \mathrm{~mm}$ working ports were used in all cases. Dilated veins were clipped without section simple in 56 cases $(75.68 \%)$. the mean operative time was $31.9 \mathrm{~min} \pm 8.6 \mathrm{~min}$. With a mean follow-up period of 27 months, we recorded $4.05 \%$ of recur-
\end{abstract}


rence and hydrocele in 1 case (1.35\%), symptoms' regression in $87 \%$ of cases and pregnancy in $65.9 \%$ of cases of infertility. Conclusion: Laparoscopic varicocelectomy is feasible and safe in our setting, with good results. We emphasize this approach in even in low setting like our own.

\section{Keywords}

Varicocele, Laparoscopy, Fertility, Pain

\section{Introduction}

Varicocele is an abnormal dilation and tortuosity of the internal spermatic veins within the pampiniform plexus veins draining the testicle. It can result in testicular discomfort, atrophy, infertility, and possibly hypogonadism [1]. Varicocele represents the most common surgically treatable cause of male infertility worldwide and is found in approximately $15 \%$ of all adult males and $40 \%$ of males presenting for infertility evaluation [2]. The clinical grading system defines varicoceles as grade 0 (subclinical): nonpalpable and visualized only by color doppler ultrasound; grade 1: palpable only with Valsalva maneuver; grade 2: easily palpable but not visible; and grade 3: easily visible. There is abundant evidence that a varicocele may alter testicular growth, spermatogenesis, and fertility potential. The cause of testicular injury is presumed to be related to increased scrotal temperature, but the pathogenesis remains poorly understood. Observation remains the approach of choice for the majority of adolescents with varicocele until a surgical indication is present. Despite the aforementioned limitations regarding testicular hypotrophy, the main indications for surgical intervention remain significant left ( $\geq 20 \%$ ) or bilateral testicular hypotrophy, pain, or abnormal semen analysis findings [1]. Several approaches exist to correct the varicocele: inguinal or subinguinal, laparoscopic or retroperitoneal, or venographic. The laparoscopic varicocele, introduced by Sanchez-de-Badajoz et al. in 1990 utilises a transperitoneal intra-abdominal approach, which offers several advantages including increased efficiency for bilateral surgery and relatively short operating times [3]. However, this approach is an intra-abdominal procedure and carries a small added risk for complications, e.g. visceral injury from trocar placement [3]. Laparoscopic varicocelectomy in an uncommon procedure in low setting where open approaches are still commonly practice. We present our experience and outcomes of laparoscopic varicocelectomy in three health structures in Yaoundé, Cameroon.

\section{Methodology}

\subsection{Study Design and Participants}

A retrospective review was performed in the files of patients who underwent laparoscopic varicocelectomy, from January $1^{\text {st }} 2010$ to November $30^{\text {th }} 2019$, in the 
Department of Surgery of three Hospital of Yaoundé (the capital city of Cameroon, a central African country): The National Insurance Fund Health Center of Essos, Bethesda Hospital and Marie Wyss Hospital. Were included all patients who have had a laparoscopic varicocelectomy for symptomatic varicocele and whom we have been able to contact again. Symptomatic varicocele was identified as patients presented with scrotal pain and/or testicular atrophy and/or infertility. The Varicocele staging was done according to the classification of Dubin and Amelar. The outcome of each patient had to be known at least one year after the surgery

\subsection{Surgical Technique}

Procedures were performed by a senior surgeon. The patient, in supine position and under general anesthesia with oro-tracheal intubation, we inserted a $10 \mathrm{~mm}$ optic port in supra-umbilical by "open-coelioscopy" and the pneumoperitoneum was achieved through this access. A $0^{\circ}$ endoscope was used and two working ports were then inserted, respectively in the iliac fossa (in the opposite site of the varicocele) and the supra-pubic region. The supra-pubic working port was of 5 $\mathrm{mm}$ diameter in all cases. The iliac fossa working port was either of $5 \mathrm{~mm}$ or 10 $\mathrm{mm}$, depending of the diameter of the endoclip used. In cases of bilateral varicocele, one working port was inserted in both flank; one of $5 \mathrm{~mm}$ diameter and another one or either 5 or $10 \mathrm{~mm}$. The internal inguinal ring was identified and the posterior peritoneum was incised 1 to $2 \mathrm{~cm}$ above. Dilated veins were identified, dissected and clipped. The internal spermatic artery was carefully spared (Figure 1).

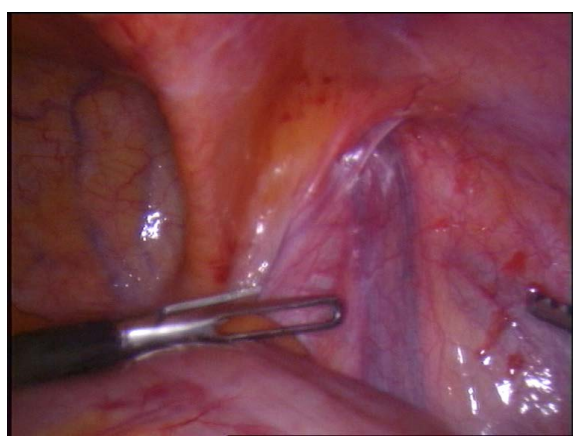

(a)

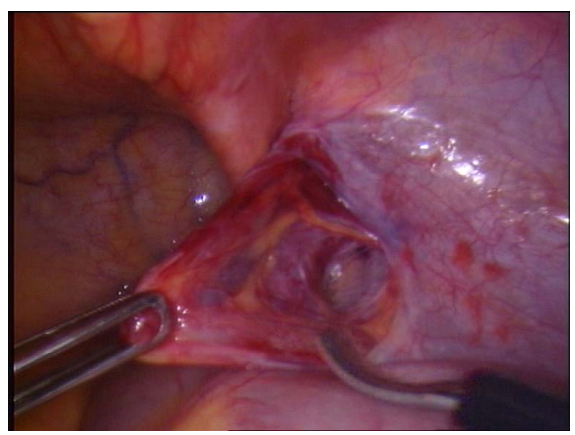

(c)

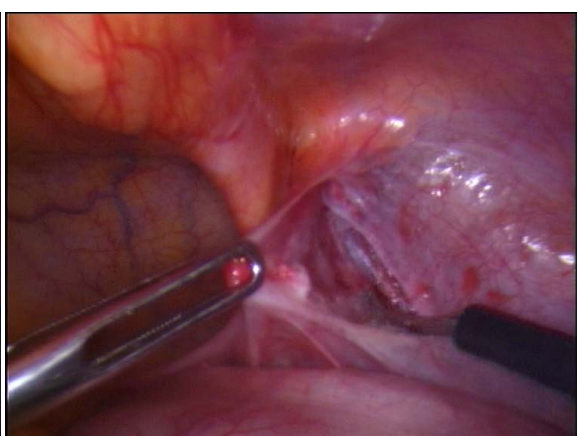

(b)

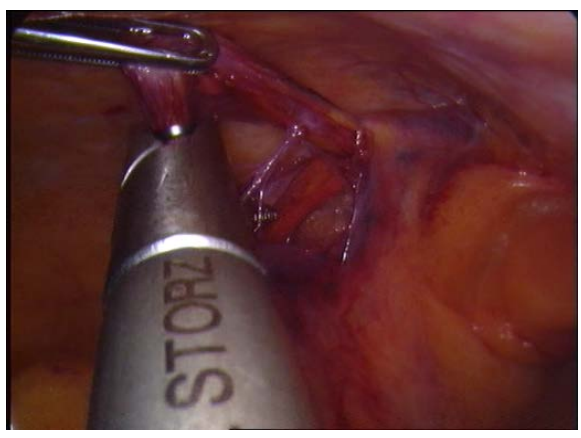

(d) 


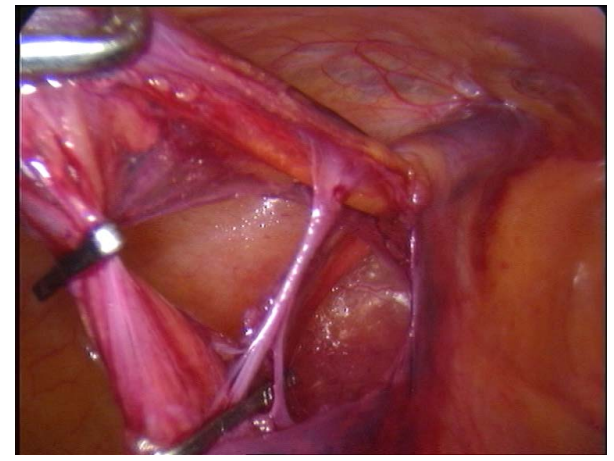

(e)

Figure 1. Laparoscopic view of varicocelectomy (a) dilated veins, (b) opening of posterior peritoneum, (c) dissection and isolation of veins, (d) endoclip, (e) clips on the veins, artery spared.

\subsection{Statistical Analysis}

For each patient, we recorded data, on demographics, clinical symptoms, ultrasound findings, operative duration, length of hospital stay, postoperative complications and outcome after surgery (in terms of recurrence, symptoms improvement and spontaneous pregnancy obtained). Data collection was done through a pre-established questionnaire by consulting patient records, operative protocol and patient registration records, by viewing videos of operating procedures. Data were analysed by using EPI Info 7.0. Means and Standard Deviations were calculated for parametric data and categorical variables were reported as counts and percentages.

\section{Results}

A total of 74 file of patients were collected.

\subsection{Socio-Demographic Characteristics}

The mean age was $36.93 \pm 9.65$ years old (range, $16-69$ years). Students are the most affected by this pathology at a frequency of $12.16 \%$ followed by traders in $8.11 \%$ of cases. Other occupations were estimated at less than $5 \%$ for each.

\subsection{Clinical Features}

Varicocele was mainly diagnosed in a context of infertility for 42 patients (56.7\%) and scrotal pain in 26 patients (35.13\%) (Figure 2). Others symptoms included scrotal discomfort $(\mathrm{n}=4,5.41 \%)$ and scrotal heaviness $(\mathrm{n}=1.35 \%)$ The infertility was primary and secondary for 28 (63.63\%) and 16 (36.37\%) patients, respectively. The average consultation time was $28.16 \pm 33.58$ months (range, 1 - 120 months). 43 (58.11\%) patients had varicocele grade 1, 21 (28.38\%) had varicocele grade 2 , and only $2(2.70 \%)$ patients had varicocele grade 3 . Our 74 patients have a total of 138 varicocelectomy procedures: 54 (72.97\%) cases were bilateral, and 20 unilateral $(27.03 \%)$. In unilateral cases, the left site was predominant in 17 (85\%) (Figure 3). 


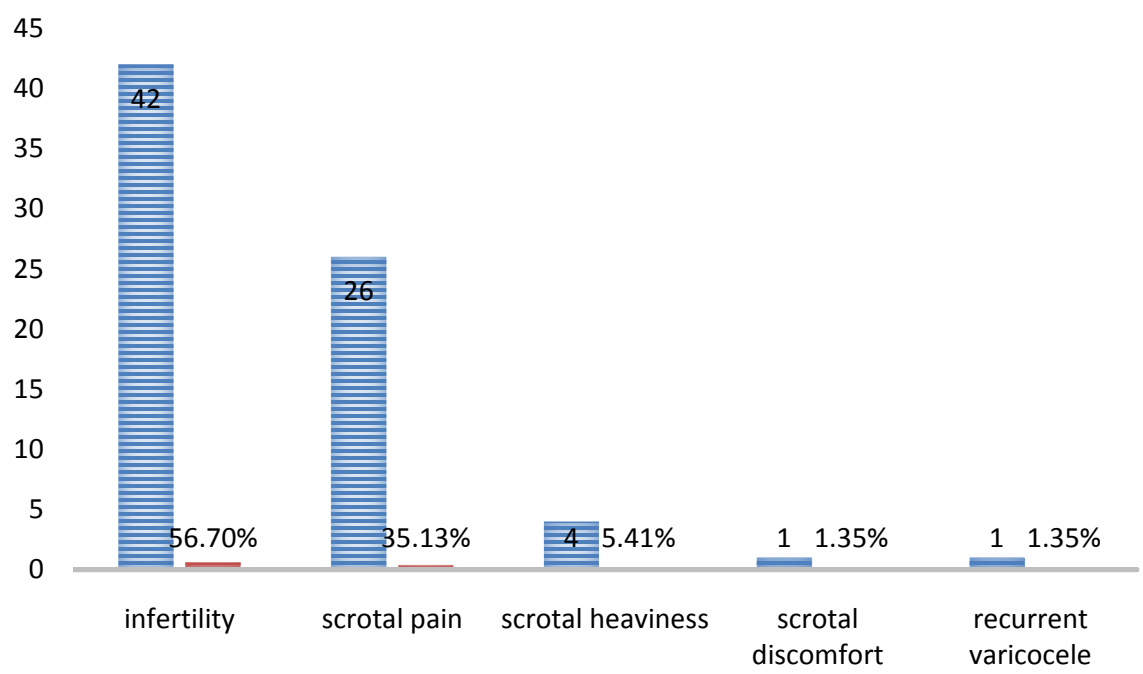

Figure 2. Indications of varicocelectomy.

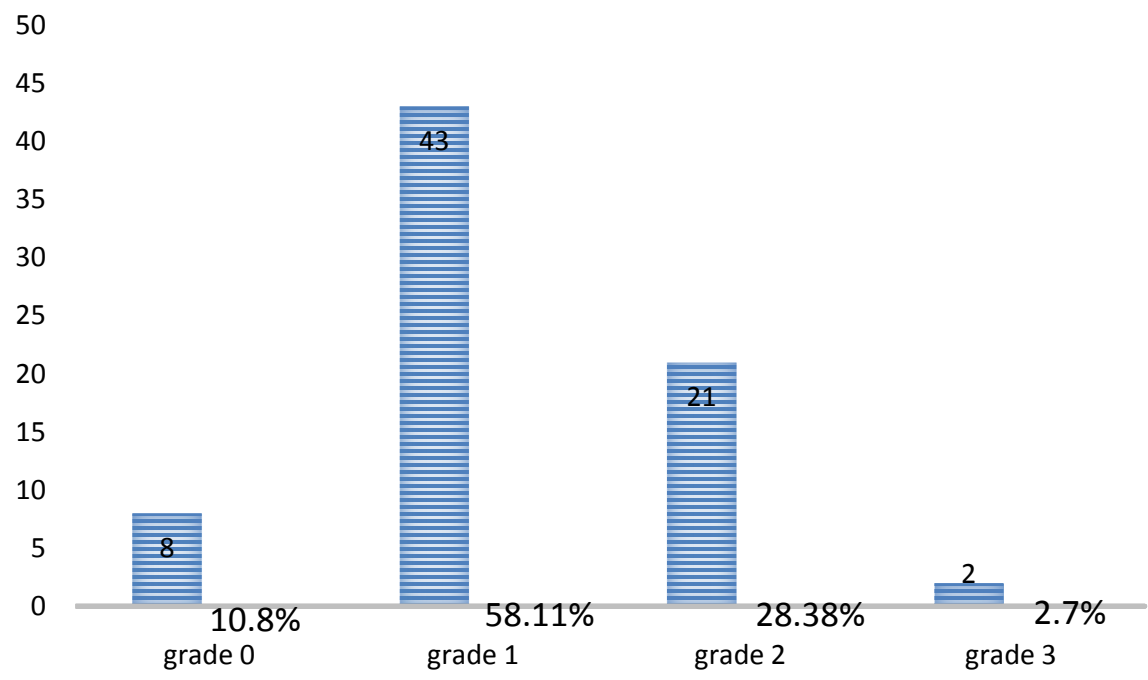

Figure 3. Grade of varicocele.

\subsection{Operative Results}

Dilated veins were simply clipped in $75.68 \%$ of cases. In the other cases $(24.32 \%)$, dilated veins were sectioned after clipping. No intraoperative complications were recorded. The mean operative time was $31.9 \pm 8.6$ minutes (range, $16-60 \mathrm{~min}$ ). All patients were discharged first day post-operative.

\subsection{Outcomes}

With a mean follow-up period of 27 months (range, 13 - 108 months). Five (5.4\%) cases of postoperative complications were recorded: one case of hydrocele $(1.35 \%), 3$ cases of recurrence $(4.05 \%)$. One reintervention (1.35\%) was performed for recurrence. There was no testicular atrophy. There was $87 \%$ percentage rate of symptom regression. 29 cases out of 44 patients $(65.9 \%)$ complaining of infertility reported spontaneous pregnancies with their partner. 


\section{Discussion}

The mean age of our patients was $36.93 \pm 9.65$. This result is comparable to that of Diao et al. in Senegal, which had an average age of 36.5 years [4]. It is a pathology that is rare before the age of 10 and therefore the incidence increases after this age [5]. On the other hand, in Morocco Benazzouz et al. [6] found a lower average age of 29.71 years. Students and traders were the most affected profession in our study. A study has shown that occupations that require prolonged standing may be risk factors for the occurrence of varicocele [7].

Our study found that infertility and scrotal discomfort were the most frequent complaints. These data do not correspond to those found by Diallo et al. [8] in Conakry. They showed that $80.7 \%$ of cases presented with infertility problem. Scrotal pain and mass followed with $10.9 \%$ and $8.4 \%$ respectively. Indeed, the prevalence of varicocele in men presenting for infertility is in the range of $25 \%$ $35 \%$, and in that subset of men with secondary infertility it is $50 \%-80 \%$ [9]. This could be related to the mentalities and habits of the populations of sub-Saharan Africa who consult only when they have a symptomatic health problem and are very little adept at the systematic health check. Moreover, it is estimated that the prevalence of pain with varicocele is around $2 \%-10 \%$ although, the association between varicocele and pain is not clearly established [10]. The average consultation time in our patients was $28.16 \pm 33.58$ months. This confirms the fact that most people in sub-Saharan Africa consult late. Thus, the longer the consultation time, the more the disease is diagnosed at an advanced stage. Out of 74 patients, bilateral and grade 3 varicocele were prevalent. These results are in total contradiction with the literature which finds the left side as the one that is most affected in $85 \%$ to $90 \%$ of cases. It is also reported that a right palpable varicocele is normally found in cases of bilateral varicocele [11]. Concerning the severity of varicocele, Diallo et al. [11] in their study revealed the following figures: on the right, grade $0(50 \%)$, grade $1(27.8 \%)$, grade 2 (22.4\%); on the left, grade 3 (49.6\%), grade 2 (33.61\%), grade $0(1.7 \%)$. On the other hand, a systematic review including 1299 men reported $32.1 \%$ of patients with varicocele grade 1, 67.9\% with grade 2 and 3 [12]. This showed that varicocele is diagnosed at a more or less advanced. The delay in the consultation of patients could be an explanation for this situation in our study.

\section{Surgical Technique}

The main operative indication was infertility in $59.5 \%$ of cases. The common indications of varicocelectomy are infertility, testicular hypotrophy and pain [13]. This is supported by other studies [10] [14] this fact shows that the couple's infertility could be considered as a common health problem with varicocele as the main correctable cause. Concerning the operative technique, we have not found any particular recommendations in the literature with regard to the diameter of the operator trocars. On the other hand, two trocar operators in iliac fossa and supra pubic or iliac fossa were enough to perform this surgery. Despite the ad- 
vent of single port laparoscopy, Esposito et al. said that three trocars is absolutely safer, technically faster, and has a lower complication rate [15]. Simple venous clipping was more performed compared to venous section after clipping. Depending on surgeon, there can be mass ligation of veins with artery, sparing artery varicocelectomy in which the spermatic veins are separated from the artery and only the veins ligated, clips, bipolar coagulation. Although, we did not find any difference in outcomes during literature review on laparoscopic varicocele repair. However, a study by Mendéz-Gallart et al. showed that the use of Ligasure ${ }^{\circledR}$ in laparoscopic varicocelectomy reduced operating time. They concluded that compared to staplers, this sealing system allows better tailoring of spermatic vessel margins, thus potentially saving lymphatic tissue [16]. The average time of the intervention was 31.9 minutes. This result is closed to the study of Esposito et al. [15] who showed that varicocelectomy by mass ligation was faster than artery sparing varicocelectomy. It varied from 14 and 45 minutes with average time of 17 minutes for the first technique. On the other hand the mean operative time was 26 minutes with range from 18 to 50 minutes for the artery sparing procedure. Then, the operating time depends on many factors including the number of trocars used, the type of varicocelectomy (artery sparing or not) and the experience of the surgical team [15] [17].

Our morbidity was of 5.4\%. Recurrence and hydroceles rate in our study were $4 \%$ and $1.3 \%$ respectively. These findings are comparable to those of the literature who found post-operative recurrence rates varying from $3 \%$ to $6 \%$ and hydrocele rates ranging from $7 \%$ to $43 \%$ [18]. We found a symptom regression rate of $87 \%$. This is similar to the $86 \%$ of success reported by Peterson et al. [19] however one study by Altunoluk et al. [20] showed that the regression of symptoms was function of the duration of the pain. The longer the symptoms last the pain regress after varicocelectomy. We noticed 29 (65.9\%) pregnancies achieved. The spontaneous pregnancy rate after laparoscopic varicocelectomy varies from $13 \%$ to $40 \%$ [21].

Limitations of our study include its retrospective nature, subject to selection bias and missing data.

\section{Conclusion}

Laparoscopic varicocelectomy is feasible, safe and reproducible even in a low setting income like our own. Results are good with high rate of symptoms' regression, high rate of pregnancy recorded, low rate of recurrence and postoperative hydrocele. We emphasize the use of this approach in the surgical management of patients with varicocele.

\section{Ethical Clearance}

Study was approved by institutional ethics committee.

\section{Conflicts of Interest}

The authors declare no competing financial or personal interests. 


\section{References}

[1] Palmer, L.S. and Palmer, J.S. (2021) Varicocele. In: Partin, A.W., Dmochowski, R.R. and Kavoussi, L.R.P.C., Eds., Campbell-Walsh-Wein Urology, 12th Edition, Elsevier, Inc., Philadelphia, 3968-3980.

[2] Pastuszak, A.W. and Wang, R. (2015) Varicocele and Testicular Function. Asian Journal of Andrology, 17, 659-667. https://doi.org/10.4103/1008-682X.153539

[3] Sanchez de Badajoz, E. and Diaz-Ramirez, F. (1990) Endoscopic Varicocelectomy. Journal of Endourology, 4, 371-374. https://doi.org/10.1089/end.1990.4.371

[4] Diao, B., Sy, M.R., Fall, B., Sow, Y., Sarr, A., Mohamed, S., et al. (2012) Varicocéle et infertilité masculine. Andrologie, 22, 29-35.

https://doi.org/10.1007/s12610-012-0157-9

[5] Miro, J., Mate, T., Jakov, T. and Tomislav, S.Z.P. (2019) Laparoscopic versus Open High Ligation for Adolescent Varicocele: A 6-Year Single Center Study. Indian Pediatrics, 15, 653-658. https://doi.org/10.1007/s13312-019-1588-1

[6] Benazzouz, M.H., Essatara, Y., Sayegh, H.E., Iken, A., Benslimane, L. and Nouini, Y. (2014) Impact de la varicocèle sur le volume testiculaire et les paramètres spermatiques. The Pan African Medical Journal, 19, 1-8. https://doi.org/10.11604/pamj.2014.19.334.4693

[7] Bolcal, C., Sargin, M., Mataraci, I., Iyem, H., Doganci, S., Kilic, S., et al. (2006) Concomitance of Varicoceles and Chronic Venous Insufficiency in Young Males. Phlebology, 21, 65-69. https://doi.org/10.1258/026835506777304719

[8] Diallo, A.B., Bah, I., Barry, M., Diallo, T.M.O., Bah, M.D., Kanté, D., et al. (2015) La varicocèle de l'adulte: Aspects anatomo-cliniques et resultats therapeutiques au service d'urologie-andrologie du CHU de Conakry Guinee. African Journal of Urology, 21, 1-5. https://doi.org/10.1016/j.afju.2015.02.002

[9] Alsaikhan, B., Alrabeeah, K., Delouya, G. and Zini, A. (2016) Epidemiology of Varicocele. Asian Journal of Andrology, 18, 179-181. https://doi.org/10.4103/1008-682X.172640

[10] Abrol, N., Panda, A. and Kekre, N.S. (2014) Painful Varicoceles: Role of Varicocelectomy. Indian Journal of Urology, 30, 369-373. https://doi.org/10.4103/0970-1591.128497

[11] Chiba, K., Ramasamy, R., Lamb, D.J. and Lipshultz, L. (2016) The Varicocele: Diagnostic Dilemmas, Therapeutic Challenges and Future Perspectives. Asian Journal of Andrology, 18, 276-281. https://doi.org/10.4103/1008-682X.167724

[12] Asafu-Adjei, D., Judge, C., Deibert, C.M., Li, G., Stember, D. and Stahl, P.J. (2020) Systematic Review of the Impact of Varicocele Grade on Response to Surgical Management. The Journal of Urology, 203, 48-56. https://doi.org/10.1097/JU.0000000000000311

[13] Cho, C., Esteves, S.C. and Agarwal, A. (2019) Indications and Outcomes of Varicocele Repair. Panminerva Medica, 61, 152-163. https://doi.org/10.23736/S0031-0808.18.03528-0

[14] Hassan, A.M. and Abdelrazek, M. (2018) Is Unilateral Varicocelectomy as Effective as Bilateral Varicocelectomy in Management of Subfertile Patients with Bilateral Varicocele. African Journal of Urology, 24, 359-362. https://doi.org/10.1016/j.afju.2018.11.002

[15] Esposito, C., Escolino, M., Castagnetti, M., Cerulo, M., Settimi, A., Cortese, G., et al. (2018) Two Decades of Experience with Laparoscopic Varicocele Repair in Children: Standardizing the Technique. Journal of Pediatric Urology, 14, 10.e1-10.e7. 
https://doi.org/10.1016/j.jpurol.2017.06.017

[16] Méndez-Gallart, R., Bautista-Casasnovas, A., Estevez-Martínez, E. and Varela-Cives, R. (2009) Laparoscopic Palomo Varicocele Surgery: Lessons Learned after 10 Years' Follow Up of 156 Consecutive Pediatric Patients. Journal of Pediatric Urology, 5, 126-131. https://doi.org/10.1016/j.jpurol.2008.10.009

[17] Li, M., Wang, Z. and Li, H. (2016) Laparoendoscopic Single-Site Surgery Varicocelectomy versus Conventional Laparoscopic Varicocele Ligation: A Meta-Analysis. Journal of International Medical Research, 44, 985-993. https://doi.org/10.1177/0300060516659824

[18] Johnson, D. and Sandlow, J. (2017) Treatment of Varicoceles: Techniques and Outcomes. Fertility and Sterility, 108, 378-384. https://doi.org/10.1016/j.fertnstert.2017.07.020

[19] Peterson, A.C., Lance, R.S. and Ruiz, H.E. (1998) Outcomes of Varicocele Ligation Done for Pain. Journal of Urology, 159, 1565-1567.

https://doi.org/10.1097/00005392-199805000-00043

[20] Altunoluk, B., Soylemez, H., Efe, E. and Malkoc, O. (2010) Duration of Preoperative Scrotal Pain May Predict the Success of Microsurgical Varicocelectomy. International Brazilian Journal of Urology, 36, 55-58. https://doi.org/10.1590/S1677-55382010000100009

[21] Lundy, S.D. and Sabanegh, E.S. (2018) Varicocele Management for Infertility and Pain: A Systematic Review. Arab Journal of Urology, 16, 157-170.

https://doi.org/10.1016/j.aju.2017.11.003 